\title{
EMPREGADAS DOMÉSTICAS, MÁQUINAS E MORAL NOS LARES BRASILEIROS
}

MAIDS, MACHINES AND MORALITY IN BRAZILIAN HOMES

\author{
Elizabeth Bortolaia Silva
}

\begin{abstract}
Resumo
Este artigo explora os debates recentes sobre o crescimento do trabalho doméstico remunerado na Europa e nos EUA, com base numa reflexão sobre o caso do Brasil. O foco é sobre as relações de gênero, classe e raça envolvidas no uso de empregadas para o trabalho doméstico, nos padrões de consumo das tecnologias de utilidades domésticas e nas discussões morais sobre as divisões hierárquicas cotidianas dentro do lar. $\mathrm{O}$ artigo considera conexões importantes entre o contexto brasileiro e o de países mais desenvolvidos, bem como as especificidades do Brasil. Baseado em observação participante, dados secundários e estudos etnográficos, um rico painel de dados empíricos é traçado para discutir as dimensões materiais e morais do trabalho e dos cuidados domésticos. Como a disponibilidade de trabalho doméstico barato configura relações de desigualdade? A exploração do caso brasileiro esclarece alguns dos problemas, contradições e possíveis consequências do fato de lares ricos nos países desenvolvidos se beneficiarem do atual deslocamento de mulheres pobres por meio da imigração internacional. $\mathrm{O}$ artigo demonstra que, no Brasil, a transferência das tensões entre mulheres e homens, na divisão do trabalho doméstico, para uma pessoa "subordinada" ' tem afetado as relações de igualdade entre homens e mulheres e também os padrões de inovação tecnológica para facilitar o trabalho em casa. Estes efeitos devem ser contemplados nas discussões sobre as consequências das tendências correntes das relações envolvidas no fenômeno da "mulher globalizada" predominante na Europa e nos Estados Unidos.
\end{abstract}

Palavras-chave: Empregadas; Tecnologias Domésticas; Moral; Brasil; Trabalho Doméstico; Divisões de Gênero.

\begin{abstract}
This paper engages with debates about the increasing use of paid domestic labour in Europe and the USA, contributing with a reflection about the case of Brazil. Relations of gender, class and race are considered in the deployment of maids for housework, the patterns of consumption of household technologies and the moral reasoning of daily living with hierarchical divisions within the home. The paper considers some parallels between the Brazilian context and that of more developed countries and also the specificity of Brazil. Based on participant observation, secondary data and an ethnographic study, rich empirical data is weaved through to discuss material and moral dimensions of domestic labour and care. How does the availability of cheap domestic labour configure relations of inequality? How are social differences in the home lived with and justified? The exploration of the Brazilian case illuminates some of the problems, contradictions and possible consequences of wealthier households benefitting from the displacement of poor women that is currently happening through international migration. The paper argues that in Brazil the deflecting of tensions in gender divisions of labour in households onto a subordinate person has affected relations of equality between women and men and also the patterns of technological innovation to facilitate housework. These are outcomes to be guarded against in Europe and the United States in face of the current trends in 'global woman' relations.
\end{abstract}

Keywords: Maids; Household Technologies; Morality; Brazil; Domestic Labour; Gender Divisions. 


\section{Introdução}

Inovações tecnológicas alteraram o trabalho doméstico dramaticamente desde o começo do século XX, em todos os países e contextos em que foram aplicadas. Isso aconteceu subsequente a mudanças na posição das mulheres na sociedade, afetando as relações entre mulheres de classes sociais diferentes e entre homens e mulheres. Estas preocupações são pertinentes, pois discussões recentes sobre o movimento migratório de mulheres têm insuflado debates sobre a globalização. Estes movimentos têm sido parcialmente influenciados pelo emprego de mulheres de países pobres em casas de países mais ricos. No Brasil, lares ricos sempre tiveram mão-de-obra barata abundante em áreas mais pobres, disponível para "importação". Como esta prática se configura nas relações de desigualdade no país? Quais são os efeitos desta prática no consumo de utilidades domésticas? Como diferenças sociais arraigadas sobrevivem no cotidiano doméstico e são justificadas? Neste artigo, a exploração destas questões tem por objetivo contribuir para reflexões ulteriores no debate corrente sobre a "mulher globalizada".

O estudo de Bridget Anderson (2000) sobre a política de trabalho doméstico na Europa contemporânea mostra a predominância de determinados grupos raciais no trabalho pago no lar e chama atenção para os efeitos perniciosos que este emprego tem nas relações entre homens e mulheres de classe média, que assim evitam conflitos e objeções a suas posições arraigadas sobre desigualdade de gênero. $O$ estudo de Anderson aponta para os conflitos de gênero e geração implicados na contratação de uma pessoa para fazer as tarefas domésticas.

Ela argumenta que o uso de trabalho pago em casa cria pessoalidade, tanto para a empregada quanto para o/a empregador/a, e ocasiona tipos singulares de relações de gênero.

Fundamental para a construção da pessoalidade, o "cuidado" entra na relação de compra e venda. Anderson argumenta, seguindo proposição de Arlie Hochschild (1997), que, quando as mulheres saem para trabalhar fora, ninguém fica em casa para cuidar do lar. As "novas" empregadas domésticas preenchem assim esse hiato. Contudo, embora o debate sobre a necessidade de "comprar amor" (enquanto "cuidado") implícita nos novos contratos de trabalho doméstico seja importante, as dimensões materiais deste trabalho, que continua sendo árduo e demorado, precisam ser mantidas em foco. Há muitas razões para se considerar concomitantemente as dimensões materiais e emocionais . Uma razão diz respeito a como ambas estão ligadas a relações desiguais atribuídas a posições de classe, gênero e raça.

Outra se refere a necessidades culturais de cuidado material e emocional, solicitadas em ambientes morais específicos, que justificam padrões de relacionamento na vida doméstica. Uma outra razão importante alude às condições materiais concretas relacionadas às demandas do estilo de vida contemporâneo. Neste artigo concentro-me especificamente nas razões que chamo "moralidade ordinária", e em como as tecnologias domésticas são utilizadas, como parte da materialidade dos modos de vida. Estas moralidades são exploradas dentro da configuração específica de relações de classe, gênero e raça prevalecentes no Brasil.

Meu argumento é que uma das consequências principais do uso difundido do trabalho doméstico pago é impedir o desenvolvimento de tecnologias para o trabalho doméstico. Este efeito político crucial tem sido negligenciado nos debates feministas sobre o trabalho doméstico. Mulheres e lares continuam à margem das preocupações sobre a inovação tecnológica (SILVA, 2002). O custo do trabalho doméstico feminino é central para o desenvolvimento de tecnologias. Embora a modernização tecnológica dos equipamentos para trabalho doméstico seja desigual globalmente, níveis diferentes de disponibilidade de trabalhadores domésticos têm um papel importante nos padrões diferenciados de inovação em regiões diferentes do mundo. No entanto, a disponibilidade de trabalho doméstico não é uma preocupação apenas numérica. Os modos pelos quais as relações sociais envolvidas nesse emprego são justificadas estabelecem o contexto moral que permite seu uso como uma das fontes consolidadoras para a posição social dos que têm condições de pagar. Os aspectos materiais e morais estão interligados.

Com base em observação participante, dados secundários e um estudo de caso no sul do Brasil, eu discuto as ligações entre empregadas domésticas, máquinas e moralidade nos lares.

O estudo etnográfico foi realizado em 1997 no sudeste do Brasil, na rica região da 
grande Campinas, no estado de São Paulo. O estudo é focado nas diferenças entre os lares pobres e os de classe média no que diz respeito ao trabalho feminino e à divisão entre gêneros nos afazeres domésticos, com uma preocupação especial sobre os efeitos do trabalho doméstico remunerado na divisão das tarefas nos lares e no consumo de tecnologias domésticas (SILVA, 1998). Não houve intenção de produzir uma amostra representativa da população em termos estatísticos. Mas eu quis captar as relações dos homens e mulheres com o trabalho doméstico e tentei incluir uma ampla gama de experiências sociais desse tipo. Famílias foram selecionadas de acordo com sua significância para a teoria, ideias e conceitos. Eu conduzi observação participante e 55 entrevistas semiestruturadas (30 mulheres e 25 homens) em 30 famílias. Todas as famílias tinham crianças dependentes, 22 das quais incluíam crianças em idade escolar (5 a 16 anos). As mulheres definiam-se como "donas de casa" em nove casas. 21 famílias autoclassificavam-se como brancas.

O caso brasileiro tem alguns paralelos com os de países mais desenvolvidos. Por exemplo, na Grã-Bretanha o crescimento do emprego feminino, particularmente o de mulheres casadas, tem sido grande desde a década de 70 do século passado, assim como no Brasil. Em uma tendência histórica mais longa, o consumo de tecnologias para o lar na Grã-Bretanha cresceu enormemente na década de 1930, quando os serviçais domésticos começaram a desaparecer rapidamente (GLUCKSMANN, 1990). Mas algumas perguntas são pertinentes sobre esses paralelos. Seria possível que as mudancas nos padrões de emprego entre homens e mulheres no Brasil estejam refletindo um processo de busca de mais igualdade entre homens e mulheres, e entre as próprias mulheres, amplamente similar ao dos países desenvolvidos? De que maneira o trabalho das mulheres fora de casa afeta os padrões da vida doméstica? O que acontece nos lares brasileiros quando as mulheres, em números crescentes, arranjam empregos fora? Enquanto o trabalho doméstico remunerado se torna uma característica corrente cada vez mais significativa entre a classe média na Europa e América do Norte (EHRENREICH e HOCHSCHILD, 2002; EJWS, 2007), através do processo de deslocamento mundial de mulheres, uma exploração do caso brasileiro, que oferece paralelos importante, é oportuna. Contradições no desenvolvimento econômico dentro do Brasil resultaram em grandes disparidades de riqueza, que de certa forma espelham os padrões de desigualdade no contexto da vida doméstica dos contextos internacionais envolvidos nas mudanças no trabalho doméstico pelo mundo, em escala global. Mas as particularidades brasileiras também são significativas.

\section{Empregadas Domésticas}

No Rio de Janeiro, no Sudeste do Brasil, Maria, a empregada, saiu da cozinha às $13 \mathrm{~h}$ para servir a comida. Ronaldo, Anita e seus filhos, Fernando (13 anos) e Manuela (16), sentaram-se em volta da mesa. Eu também me sentei para comer, como amiga de Anita. Tivemos salada como entrada, quatro pratos quentes à nossa escolha, duas sobremesas e bebidas geladas $\mathrm{e}$ quentes. Era um dia de semana normal. Quando a refeição terminou, todos foram lidar com seus assuntos pessoais e a mesa foi deixada para Maria limpar. Maria morava em um pequeno quarto em uma parte isolada da casa, adjacente à cozinha. Essa é a "área de serviço", onde as roupas são lavadas e passadas e a comida é feita, fora da vista dos habitantes e das visitas.

Maria só era vista quando servia água e café, na hora das refeições, ou quando ela, silenciosa e discretamente, fazia as camas, esfregava o chão e limpava os banheiros de manhã. Maria acordava antes das $7 \mathrm{~h}$ para servir o café da manhã e ficava acordada até depois das $21 \mathrm{~h}$, limpando a mesa após o jantar. Maria viera do Nordeste e trabalhava para Anita há cerca de 10 anos. Anita dependia de Maria para todo o trabalho na casa. Anita era uma acadêmica, como eu. Ela estudava a pobreza e a reforma agrária no Nordeste. Ela não poderia imaginar seu dia a dia sem "uma" Maria. Ela não se engajou nas minhas tentativas de conversar sobre criados e desigualdade social. Anita era brasileira. Todas as pessoas nesse cenário são brancas.

No Recife, no Nordeste do Brasil, Vanya saiu para fazer compras com Janice, sua cozinheira. Janice empurrou o carrinho, pegou os produtos e colocou as sacolas no carro. Vanya disse a Janice o que comprar, pagou e dirigiu o carro. Em casa, Janice tirou as sacolas do carro e guardou os produtos. Enquanto isso, a babá, Teresa, cuidava de Julian, de cinco 
anos, mantendo-o fora do caminho para que Cida, a faxineira, pudesse fazer seu trabalho. Eu era uma amiga de Vanya, hospedada por alguns dias. Eu não podia nem fazer uma xícara de chá ou pegar um copo de água na cozinha. Sempre que passava pela porta, uma das criadas se oferecia para atender minhas necessidades. Vanya era uma acadêmica, como eu, fazendo estudos sobre sexualidade e "raça". Ela não podia conceber uma vida de cuidar de crianças, cuidar da casa, relacionar-se com seu marido e fazer pesquisas sobre "cultura" sem uma Janice, uma Teresa e uma Cida. Vanya era inglesa. Todos nesse cenário são negros, exceto minha amiga e eu.

Estas são duas histórias de pessoas com níveis culturais e sociais muito diferentes. Todas estão imersas em um mundo de profunda desigualdade social. Anita sozinha ganhava dez vezes mais do que o que pagava a Maria. Maria tinha uma longa jornada de trabalho, não tinha previdência social, casa própria, nem aposentadoria ou segurança de emprego. Elas tinham a mesma idade. Vanya pagava para suas três empregadas no Recife o mesmo que Anita pagava somente à Maria no Rio. É por isso que a nordestina Maria sentia-se tão grata por ter seu emprego no Rio de Janeiro. Tanto Anita quanto Vanya tinham maridos que ganhavam ainda mais do que elas. A renda de cada uma das famílias era cerca de 40 vezes maior do que o salário de suas criadas. Os maridos eram vistos por Anita e Vanya como homens sensíveis, bons provedores e oferecedores de grande apoio. Eles não ajudavam em casa nem com as crianças. De qualquer forma... nem eu conseguia pegar um copo de água sem que este viesse servido por uma empregada em uma bandeja!

Por que era tão fácil para minhas amigas abastadas viverem uma vida confortável com tanta desigualdade social clamando de dentro de suas próprias casas? A facilidade de acesso ao trabalho de outros obviamente derivava de desigualdades econômicas. Mas as questões morais também eram significativas. De que modo isso era visto como um jeito "apropriado" de administrar uma casa? Que consequências políticas isso tinha num contexto econômico e social mais abrangente? Além disso, como estas práticas podiam coexistir com as transformações contemporâneas da posição da mulher no mercado de trabalho e na sociedade?

Uma das mudanças mais significativas no Brasil desde os anos de 1970 foi a participação crescente das mulheres no mercado de trabalho. Isso está ligado às necessidades econômicas e demandas empregatícias, mas também a mudanças culturais e demográficas, como a redução das taxas de fertilidade e o aumento do nivel educational. Já em 1995, 40\% da força de trabalho brasileira era feminina. Este índice chegava em 2001 a $45 \%$ na mais desenvolvida Região Metropolitana de São Paulo(SEADE, 2002). Em 2005, 53\% das mulheres faziam parte da população economicamente ativa (Fundação Instituto Brasileiro de Geografia e Estatística, FIBGE, in BRUSCHINI, 2007, tabela 1). O aumento tem sido maior nas áreas urbanas e nas regiões mais desenvolvidas. Mulheres casadas, amasiadas e separadas (incluindo as divorciadas) têm influenciado mais no aumento da taxa de emprego do que as mulheres solteiras. Desde 1993 mais da metade das mulheres casadas encontram-se trabalhando fora (Pesquisa Nacional por Amostra de Domicílios, PNAD,1993).

A etnia tem influenciado fortemente a posição das mulheres na estrutura de emprego. Um estudo recente feito pela Organização Mundial do Trabalho, baseado em dados estatísticos brasileiros (PNAD, 2001), demonstra que a diferença entre mulheres brancas e negras empregadas como "domésticas" é grande: $24 \%$ das negras contra $14 \%$ das brancas (ILO, 2005 , p. 3). Ainda assim, a proporção de mulheres em geral empregadas em trabalho doméstico tem diminuído particularmente nas áreas urbanas mais desenvolvidas, onde este tipo de trabalho é proeminente (BRUSCHINI, 2000; 2007).

Em um incremento relacionado, o consumo de tecnologias para o trabalho doméstico tem crescido desde os anos 1960 (TOLEDO, 1989; NETO, 1992; ABINEE, 1994, 2005; GITAHY et al., 1997). O consumo destas tecnologias deve-se ao aumento do poder aquisitivo, à diminuição do preço dos produtos, à tendência de unidades familiares menores e também a diferentes modos de lidar com as demandas do lar. Em termos de nível de riqueza, cor da pele e emprego no trabalho doméstico, os lares do meu estudo mostram um quadro notável de desigualdade e subordinação no espaço do lar. A cor da pele fica mais branca conforme a 
renda aumenta. O uso de trabalho doméstico remunerado aumenta conforme a renda cresce e a brancura da pele clareia.

Tabela 1 - Renda, etnia e trabalho doméstico remunerado

\begin{tabular}{|c|c|c|c|c|c|}
\hline $\begin{array}{c}\text { Nível de } \\
\text { renda }\end{array}$ & Baixa & $\begin{array}{l}\text { Média- } \\
\text { baixa }\end{array}$ & Média-alta & Alta & Alta-alta \\
\hline $\begin{array}{l}\text { Número de } \\
\text { famílias e } \\
\text { etnia }\end{array}$ & $\begin{array}{l}\text { Três N } \\
\text { Uma P } \\
\text { Duas B }\end{array}$ & $\begin{array}{l}\text { Uma N } \\
\text { Uma N/P } \\
\text { Cinco B }\end{array}$ & $\begin{array}{l}\text { Uma N/P } \\
\text { Uma B/P } \\
\text { Quatro B }\end{array}$ & $\begin{array}{l}\text { Uma N } \\
\text { Seis B }\end{array}$ & Quatro B \\
\hline $\begin{array}{l}\text { Número de } \\
\text { empregadas }\end{array}$ & Nenhum & $\begin{array}{l}\text { Duas } \\
\text { faxineiras }\end{array}$ & $\begin{array}{l}\text { Uma } \\
\text { faxineira }\end{array}$ & $\begin{array}{l}\text { Uma } \\
\text { empregada } \\
\text { que pousa na } \\
\text { casa; } \\
\text { Cinco } \\
\text { empregadas; } \\
\text { Três } \\
\text { faxineiras }\end{array}$ & $\begin{array}{l}\text { Quatro } \\
\text { empregadas } \\
\text { (uma das quais } \\
\text { também } \\
\text { lavadeira e outra } \\
\text { babá que pousa } \\
\text { na casa) }\end{array}$ \\
\hline $\begin{array}{l}\text { Proporção de } \\
\text { não-brancos / } \\
\text { brancos }\end{array}$ & $\begin{array}{l}\text { Quatro / } \\
\text { Seis }\end{array}$ & $\begin{array}{l}\text { Dois / } \\
\text { Sete }\end{array}$ & Dois / Seis & Um / Sete & Zero / Quatro \\
\hline
\end{tabular}

A tabela 1 indica que o lugar dos indivíduos na sociedade e seu acesso ao trabalho de terceiros baseia-se firmemente na classe de renda. A proporção de famílias em cada nível de renda neste estudo está longe de ser estatisticamente representativa. Há uma amostra deliberadamente maior de rendas mais altas por causa de uma preocupação com os efeitos do trabalho doméstico pago na divisão do trabalho entre os gêneros e nas desigualdades dentro do lar. No Brasil como um todo, à época do meu estudo, mais de $50 \%$ da população ganhava abaixo de dois salários mínimos (somente uma das famílias estudadas tinha renda tão baixa), com somente $5 \%$ ganhando mais de 10 salários mínimos (24 famílias deste estudo ganhavam mais que o equivalente a 10 salários mínimos). A região investigada é uma das mais ricas do Brasil, com uma população que ganha salários muito mais altos do que os do resto do país. Portanto, era de se esperar que uma representação estatística destas variáveis mostraria uma disparidade muito maior do que aquela que é qualitativamente representada neste artigo. Eu indiquei cinco tipos de categorias de renda para abranger o gradiente de uma disparidade de riqueza muito alta. Todos os trabalhadores domésticos pagos eram mulheres.

A maioria das mulheres (21) nos lares investigados trabalhava fora de casa. Sete não tinham renda e duas ganhavam pequenas quantias, uma para cuidar de crianças e outra para fazer projetos arquitetônicos. Todas eram mães de crianças pequenas e cinco eram mães solteiras. A maioria tinha agendas diárias atribuladas. As mulheres contribuíam com metade ou mais da renda da casa em mais de um terço das famílias. Somente quatro mulheres eram as únicas provedoras (duas delas eram mães-solteiras), e todas essas pertenciam ao grupo de baixa renda. Três das mulheres no grupo de baixa renda trabalhavam como empregadas em casas mais ricas. Estas foram as únicas empregadas domésticas incluídas no estudo. Elas foram estudadas no contexto de suas casas, nãao como empregadas em outras casas. ${ }^{1} \mathrm{~A}$

\footnotetext{
${ }^{1}$ Eu não comparei a casa das empregadas com a dos seus empregadores e não tratei as três mulheres entrevistadas que trabalhavam em serviço doméstico como empregadas. Elas são classificadas como mulheres de lares pobres para os propósitos deste estudo. Para acesso à voz das empregadas em relação a sua ocupação e vida em família, ver Brites (2001).
} 
renda das mulheres era absolutamente significativa para a economia de seus lares quando no grupo de baixa renda, mas também era importante na renda dos lares de classe média-alta e alta. Apesar disso, a renda das mulheres não alterava seu status no lar de modo significativo. Isto é confirmado pelo estudo de Cynthia Sarti (1996) sobre famílias pobres em São Paulo, no qual ela argumenta que a distribuição de "autoridade" na família baseia-se nos papéis diferentes, e tradicionais, de homens e mulheres.

Entretanto, nas famílias que estudei, com frequência era a renda das mulheres que determinava objetivamente a posição de seu lar em uma classe mais alta. Somente na classe média (baixa a alta) foram encontradas mulheres que não contribuíam com a renda doméstica. $\mathrm{Na}$ classe média-baixa uma estratégia conservadora de ter um único provedor era mais comum. Embora as mulheres ganhassem bem mais na classe alta-alta, sua renda não fazia diferença para a riqueza de suas casas. Os homens tinham rendas suficientemente altas por si mesmos neste grupo. Como um todo, a participação significativa das mulheres no mercado de trabalho não refletia uma contribuição igualmente importante nas fontes financeiras da casa: o ganho das mulheres era mais importante quando a privação era maior, mas não tinha impacto significativo nos níveis de riqueza totais dentro do grupo melhor posicionado.

A rotina diária das mulheres nos lares mais ricos (classes alta e alta-alta), que tinham empregadas domésticas, parecia totalmente separada da rotina das suas crianças. As atividades das mães mais abastadas com as crianças envolviam levar e pegar na escola, dar comida à noite e colocar na cama. Acordar as crianças e servir o café da manhã e o almoço era feito predominantemente pelas empregadas ou babás. Em uma das casas, a empregada tinha de dar comida na boca de uma criança de quatro anos, mas a mãe não considerava isso uma das atividades implícitas em cuidar da casa. As crianças nas classes alta e alta-alta davam ordens às empregadas e esperavam que seus caprichos fossem inteiramente atendidos, ou senão as empregadas seriam "dedadas". Para um grupo de crianças privilegiadas, a cultura de ser servido por uma pessoa de classe mais baixa (geralmente, uma mulher) fazia parte de sua criação.

Existem basicamente três modos de as mulheres que fazem trabalho doméstico sem pagamento diminuírem seu fardo. Um é empregar (ou forçar) alguém para fazer o trabalho, ou parte dele. Outro é pressionar as autoridades estatais ou municipais para que forneçam alguns serviços públicos para diminuir as tarefas. O terceiro modo é comprar tecnologias domésticas para facilitar o serviço. Estas três estratégias podem ser combinadas. Este artigo considera o primeiro e o terceiro modos de diminuir o peso do trabalho nos lares, pois a pesquisa não encontrou evidências de o governo ser pressionado em questões sobre o fardo do trabalho doméstico, nem a nível local nem nacional. No entanto, eu reflito sobre a intervenção governamental no serviço doméstico na conclusão.

\begin{tabular}{|c|c|c|c|c|c|c|}
\hline \multirow{2}{*}{ Tecnologia } & \multicolumn{5}{|c|}{ Renda } & \multirow{2}{*}{$\begin{array}{l}\text { Número total } \\
\text { de tecnologia }\end{array}$} \\
\hline & baixa & média-baixa & média-alta & alta & alta-alta & \\
\hline Fogão & 6 & $8 \mathrm{c}$ & 6 & $8 \mathrm{c}$ & 4 & 32 \\
\hline Micro-ondas & - & 4 & 5 & 7 & 4 & 20 \\
\hline Geladeira & 6 & 7 & 6 & 7 & 4 & 30 \\
\hline Freezer & 1 & 7 & 4 & 7 & 4 & 23 \\
\hline Lava-louças & 1 & - & 1 & 5 & 3 & 10 \\
\hline $\begin{array}{l}\text { Tanquinho / Máquina } \\
\text { de lavar roupa }\end{array}$ & $5 / 1$ & $4 / 7 a$ & $4 / 4 b$ & 17 & $/ 4$ & $13 / 23$ \\
\hline Secadora & - & 1 & 2 & 6 & - & 9 \\
\hline Total de famílias & 6 & 7 & 6 & 7 & 4 & $30 /-$ \\
\hline \multicolumn{7}{|c|}{$\begin{array}{l}\text { Legenda: } a=4 \text { máquinas de lavar eram usadas por donas de "tanquinho" somente como } \\
\text { centrifugadoras. } \\
\qquad b=2 \text { máquinas de lavar antigas usadas somente como centrifugadoras. }\end{array}$} \\
\hline
\end{tabular}




\section{Figura 1 - Posse de tecnologia por nível de renda}

\section{Máquinas}

A posse de tecnologias domésticas tem crescido visivelmente no Brasil. Todas as famílias que estudei tinham fogão, geladeira e máquina de lavar ou equivalente (ver figura 1). Entretanto, segundo estimativas, na metade da década de 1990 , somente $75 \%$ dos lares brasileiros tinham tanto geladeiras quanto fogões (ABINEE, 1994).

Estas são tecnologias domésticas usuais em países como a Grã-Bretanha e os Estados Unidos. A máquina de lavar possuída por $1 / 6$ das famílias era do tipo mais básico, chamado tanquinho. Este é uma tina com capacidade para $4 \mathrm{~kg}$ de roupa, que enche automaticamente de água, tem um compartimento para alvejante, mas não para sabão, e desliga automaticamente. Tanquinho não centrifuga. Cinco das seis famílias mais pobres tinham um tanquinho, enquanto quatro tanquinhos pertenciam a casas de classe média-baixa e mais quatro a casas de classe média-alta. No entanto, os dois últimos grupos também possuíam máquinas de lavar mais velhas, que eram usadas para centrifugar as roupas lavadas no tanquinho. Somente os dois grupos de maior renda não possuíam nenhum tanquinho, porque tinham acesso a máquinas de lavar de melhor qualidade. Claramente, o trabalho de lavar a roupa é mais difícil com equipamentos de menos qualidade. Torcer roupas à mão ou transferir a roupa do tanquinho para centrifugar aumenta o trabalho consideravelmente. Mas a posse de tecnologia de qualidade não significa necessariamente facilidade nas tarefas da casa.

Em dois domicílios, dois fogões estavam em uso. Na casa dos Montes, o fogão mais novo tinha sido um presente da mãe do homem. Foi instalado em posição oposta ao fogão velho, que era usado para frituras e para cozinhar comidas mais "sujas" ou que demoravam mais. Na casa dos Oliveira, havia duas cozinhas. Uma cozinha nova inteiramente equipada tinha sido construída recentemente e a velha tinha virado uma área da "casa de serviço", onde a empregada cozinhava. Mas a geladeira ainda não tinha sido instalada, e a empregada precisava andar cerca de 10 metros entre o fogão, onde ela cozinhava na "casa de serviço", e a geladeira, na nova cozinha dentro da casa. Essa era sua rotina diária havia seis meses. Depois de lavar a louça à mão na "casa de serviço" (ela não tinha permissão para usar a lavalouças), a empregada levava os pratos, panelas e talheres para a nova cozinha, onde eram guardados. A nova cozinha só era usada nos fins de semana, pela dona da casa.

Conquanto esse uso de duas cozinhas é excepcional; esta prática tem uma contrapartida histórica curiosa. Nos tempos coloniais, quando a escravidão era preponderante, nos lares mais abastados era comum ter duas cozinhas. A cozinha "limpa" ficava dentro de casa, a "suja", fora. Na cozinha "suja", doces trabalhosos e sobremesas eram cozinhados, e as tarefas mais pesadas e menos higiênicas eram executadas. Uma explicação para essa divisão espacial das atividades de cozimento enfatiza que, ao contrário da Europa, onde o calor do forno contribuía para o aconchego, o clima brasileiro tornava o fogão um objeto indesejável no espaço doméstico (ALGRANTI, 1997). No entanto, existem referências de que mesmo na fria região do sul do país a boa culinária era feita em pequenas tendas construídas no quintal das casas (SAINT-HILAIRE, 1820-21), uma explicação que pode sugerir que cozinhas externas tinham por objetivo instituir uma separação espacial que refletia as divisões sociais entre senhores e escravos (LEMOS, 1989), o que ecoa as relações atuais entre empregadas e empregadores. Como Rita Oliveira me disse: "eu construí uma cozinha externa para as empregadas porque cansei de vê-la arranhada. Elas [as empregadas] destruíam tudo".

Os modos pelos quais o desempenho das tarefas domésticas cotidianas é facilitado ou dificultado refletem as divisões sociais desiguais. Por exemplo, é tido como certo que a eletricidade não deve ser usada se puder ser substituída pelo trabalho das empregadas, e também é amplamente difundido que as empregadas podem estragar as tecnologias domésticas se forem autorizadas a usá-las. Muitas histórias de estragos, ou de estratégias de proteção pelas patroas, foram contadas. 
"Lavar está incluído no pagamento dela." [Explicando o porquê da empregada não usar a lavalouças] (...) "O fogão era auto-limpante, mas ela [a empregada] usou um produto para remover sujeira e corroeu o interior." (Nina)

"Tenho medo que ela [a empregada] quebre. Ela não presta atenção nas tarefas [como usar a lava-louças]." (Márcia)

"Ela não sabe usar [o forno de micro-ondas] e ela não precisa usá-lo." [Sim, essa empregada cozinhava todo dia.] (...) "A lava-louças quebrou várias vezes na mão da empregada... mas se você não tiver uma lava-louças nenhuma empregada fica com você." (Inês)

"Eu nunca disse a ela [a empregada] para não usar [a lava-louças]. Mas acho que ela nem sabe como funciona." (Eunice)

De um ponto de vista sociológico e econômico, a racionalidade de tais práticas repousa tanto no baixo custo do trabalho das empregadas como no custo relativamente alto da eletricidade e da tecnologia. $\mathrm{Na}$ base destas razões está também a falta de habilidades para operar máquinas devido à baixa escolaridade e à ausência de treinamento na operação de equipamentos para as pessoas que deviam de fato ser suas principais usuárias: as empregadas. As mulheres empregadas para fazer o trabalho doméstico nos lares que têm de tudo (ver tabela 1 e figura 1) eram inaptas para fazer uso dos equipamentos projetados para tornar os afazeres do lar mais fáceis, melhores e mais eficientes. Esta tecnologia era predominantemente usada nos fins de semana, quando o acesso ao trabalho das serviçais não estava disponível. O uso corrente do trabalho doméstico é despojado de cuidado e é ineficiente porque é barato e abundante. Treinamento não é fornecido, tarefas não são tornadas mais fáceis. Estas práticas são corroboradas pela moralidade social que prevalece no país.

\section{Moral}

Como as pessoas estão envolvidas nessas práticas, e como elas as justificam, quando fazem parte de uma diferenciação social tão profunda?

Eu explorei a "moralidade ordinária" do trabalho doméstico através da aplicação de uma vinheta aos participantes do meu estudo. Minha preocupação era com uma moral específica - ou ética do cuidado. Como definida por Tronto (1993), isto se refere a sentimentos morais, e não à razão. É a moral das experiências diárias e dos problemas morais das pessoas reais em sua vida cotidiana. Em termos práticos, meu método envolveu ler uma estória curta em forma de vinheta para uma pessoa entrevistada, e perguntar sua opinião sobre o que os personagens da estória deveriam fazer. Eu apliquei quatro vinhetas neste estudo. O raciocínio moral retratado pela estória que eu apresento neste artigo é espelhado nas outras três, embora cada uma vise dilemas diferentes da vida doméstica. Eu conversei com cada adulto separadamente.

A vinheta explorada aqui é uma longa estória sobre o relacionamento de uma família com a empregada. Eu usei o método de construir uma dimensão temporal e alterar as circunstâncias dos personagens num estágio posterior. Os respondentes eram convidados a fazer uma escolha sobre o que "deveria" acontecer no primeiro, segundo e terceiro estágios. Isto aumentou a complexidade da minha estória. A estoria em forma de vinheta geralmente acarretava a narração de estórias relacionadas com a experiencia pessoal do/a respondente, seus amigos e famílias. A hipótese inerente a este método é que os significados são sociais e que a escolha de uma ação específica traz à tona tanto a moral pública quanto a moral pessoal dos relacionamentos (FINCH, 1987; FINCH e MASON, 1993).

A estória é uma situação hipotética baseada em acontecimentos da vida real. $\mathrm{O}$ contexto é típico do Brasil e a linguagem reflete relacionamentos e suposições tidas como certas sobre o papel dos indivíduos. Por exemplo, dirigir-se à empregada usando "Dona" antes do nome é frequentemente um sinal de respeito, indicando que ela é mais velha, mas também pode transmitir uma ideia de afeição ou definir uma distância social. Um homem que cuida do filho com a assistência de uma empregada que pousa na casa em tempo integral claramente não está fazendo isso sozinho. Quando a estória diz que está, coaduna-se com a invisibilidade 
do trabalho da empregada. Os/as respondentes podem tanto fazer comentários quanto concordar com isso.

Isabel e Sérgio tinham um filho de sete anos, Pedro. Eles moravam em uma casa grande e confortável. Ambos trabalhavam em tempo integral e a empregada, Dona Margarida, trabalhava para eles há quatro anos. Dona Margarida cuidava da casa e de Pedro, levando-o diariamente à escola, e era uma excelente cozinheira. Ela morava na casa e tinha os sábados e domingos de folga. Isabel morreu repentinamente e Sérgio teve que cuidar de Pedro sozinho. Dona Margarida continuou trabalhando do mesmo jeito que antes. Sérgio e Pedro nunca limpavam a mesa, lavavam a louça ou arrumavam as camas. Eles tomavam banho de manhã e deixavam as toalhas molhadas no chão do banheiro. Era sempre Dona Margarida que cuidava de tudo. E agora ela fazia algumas das coisas que Isabel costumava fazer. Seu trabalho aumentou e ela estava cansada. Você acha que Dona Margarida deveria:

- Pedir um aumento de salário para Sérgio.

- Pedir para Sérgio contratar uma ajudante para ela.

- Largar o emprego.

- $\quad$ Pedir para Sérgio e Pedro fazerem algumas das tarefas que Isabel costumava fazer antes.

Os/as respondentes que eram pobres (nos dois grupos de renda mais baixos) tendiam a se identificar com a empregada mas temiam que ela deixasse o emprego, pois seria difícil encontrar outro e o menino órfão era ligado a ela. Porque ela era claramente importante para a família, ela deveria insinuar a necessidade de compensação para seu esforço crescente. Como prioridade, ela deveria mencionar a necessidade de uma ajudante, mas deveria aceitar o que o patrão escolhesse the dar: uma ajudante ou o aumento de salário. Respondentes mais abastados tendiam a enfatizar a ligação emocional. Mais da metade dos/das respondentes (29) sugeriram que a empregada deveria pedir que o pai e o menino fizessem as tarefas que a falecida mãe costumava desempenhar, enquanto quase metade deles/delas (21) não comentaram sobre o fato de que Sérgio e Pedro criaram tarefas novas para Dona Margarida.

Entretanto, os/as mais ricos/as eram mais propensos/as a sugerir que o pai e o filho deveriam fazer algumas tarefas, enquanto a maioria das mulheres de baixa renda disse que Dona Margarida deveria ter uma ajudante. Talvez essas mulheres acreditassem que a "ajuda" que ela conseguiria de Sérgio e Pedro não seria muito efetiva. Somente uma pessoa, um homem (de classe alta-alta), disse que a empregada deveria largar o emprego. Independentemente da escolha do/a respondente, eu prossegui com a vinheta, desdobrando a estória.

Dona Margarida não pediu nada, e continuou fazendo seu trabalho e se cansando. Um ano mais tarde, Sérgio arranjou uma namorada, Cléia, que veio morar na casa. O trabalho de Dona Margarida aumentou porque Cléia fazia a mesma coisa que Sérgio e Pedro. E Cléia e Dona Margarida não se davam bem. O que você acha que Dona Margarida deveria fazer?

- Pedir um aumento de salário para Sérgio.

- Pedir para Sérgio contratar uma ajudante para ela.

- Largar o emprego.

- Pedir para Sérgio, Pedro e Cléia colaborarem fazendo algumas das tarefas.

No segundo episódio, eu apresentei a situação como ela se desdobrou um ano mais tarde. Isto contradisse a opinião prévia de alguns/algumas respondentes. Eu deliberadamente retratei uma empregada de personalidade submissa, para testar a moral do comando relações de submissão, visto que minha preocupação principal era como as relações de desigualdade eram percebidas e tratadas no lar. Isto não implica que os serviçais nos lares brasileiros sejam todos submissos como Dona Margarida afigura-se nesta vinheta. Na verdade, muitas práticas de resistência também são encontradas, descritas por Jurema Brites (2001, p. 119-128) como uma tática sutil de insubordinação, que inclui "emprestar" roupas sem permissão dos empregadores e roubar comida ou objetos.

$\mathrm{Na}$ vinheta, a empregada continuou como antes, nunca fazendo nenhuma exigência nem deixando seu patrão saber que ela se sentia sobrecarregada. A nova namorada, vivendo 
na casa, agia exatamente como o pai e o menino. O trabalho da empregada aumentava. Eu convidei os/as respondentes a dizerem o que Dona Margarida deveria fazer, repetindo as mesmas alternativas de antes. A dimensão de gênero tornou-se relevante desta vez. A resposta mais comum agora, principalmente das mulheres, era que a empregada deveria deixar o emprego. Isto porque uma mãe substituta em potencial havia surgido, mudando a situação e criando conflito. Dona Margarida estava então livre dos laços emocionais imputados. $O$ interessante é que, diferentemente da primeira situação, agora aqueles/aquelas com rendas mais altas disseram predominantemente que Dona Margarida deveria largar o emprego, acentuando a dimensão de gênero do cuidado, no qual a namorada poderia substituir o trabalho emocional da empregada, e corroborando a prudência dos/das respondentes mais pobres em perder um emprego.

Eu então continuei com a estória até um episódio final, no qual a empregada optou por não pedir nada, mas um ano depois perdeu seu emprego devido a conflitos crescentes com a namorada. No entanto, Dona Margarida conseguiu outro emprego em uma casa vizinha. Seis meses depois, Sérgio entrou em contato pedindo que ela voltasse: ele tinha terminado com a namorada. Eu não ofereci nenhuma alternativa, mas perguntei de novo: o que você acha que Dona Margarida deveria fazer?

Alguns/algumas respondentes achavam que ela devia continuar onde estava, mas mais da metade, em proporção similar entre os gêneros, achava que ela devia retornar ao antigo emprego por causa dos laços emocionais com o menino e seu pai.

Ela não pode abandonar a crianças porque ela o ama. Ela deveria voltar por causa do menino - ele é como um filho... E pedir uma ajudante! (Maria)

Ela deveria voltar porque havia uma amizade e isso conta muito. (Sandro)

Na verdade ela ajudou a criar o menino. Ela já tinha intimidade com a casa. Volte! (Cristina)

Numa inversão do padrão do round anterior, as sugestões de que Dona Margarida deveria voltar ao emprego antigo predominaram entre os/as de renda mais alta, enquanto os/as de renda mais baixa tendiam a concordar que ela não deveria voltar. A resistência dos/das mais pobres em ser joguete dos/das mais ricos/as veio à tona. O medo de perder o emprego não mais existia. Mas os/as mais ricos/as sentiram a perda do cuidado, e a ligação emocional com a empregada era invocada. Tanto a aceitação passiva e a resistência, bem como os laços afetivos, eram aparentes na reação a esta vinheta, indicando um relacionamento complexo entre a pobreza e a obediência, o dinheiro e o afeto.

Com a importante ressalva deste último momento da estória, quando os/as mais pobres escolhiam que a empregada não deveria voltar ao antigo emprego, esta vinheta mostra que as escolhas dos/das respondentes eram consistentes com a moral prevalecente, que prescreve a dedicação dos despossuídos para com os abastados. Isto reflete o que Teresa Sales (1994), em seu estudo sobre o nordeste do Brasil, classificou como a "cultura política da dádiva". Ela implica passividade e gratidão do recebedor em face do donatário e refere-se a uma história em que escravos eram dispensáveis, dependendo da "dádiva" de seus superiores para a própria sobrevivência. Deste contexto, como observado por vários analistas (KOWARICK, 1987; LOPES e GOTTSCHALK, 1990), desenvolveu-se uma cultura de submissão política e social. Aqui a empregada não era simplesmente uma trabalhadora, mas uma cuidadora devotada. Entretanto, a aceitação, pelos/as respondentes, de que os homens abdiquem do trabalho doméstico e do cuidado não se aplica igualmente às mulheres. A mulher falecida costumava fazer algumas tarefas como limpar a mesa, lavar a louça à noite, fazer as camas e pegar as toalhas molhadas do chão do banheiro. Isso mostra que mulheres abastadas podem efetivamente pôr mãos à obra em trabalhos domésticos leves, apesar do ideal colonial retratado em novelas contemporâneas de "madames" evitando todo tipo de esforço físico.

Esperava-se que a namorada também fizesse as tarefas da casa, e não que se comportasse como o pai e o menino. Como ilustrado pelo comentário de Regina: "ela deveria voltar... depois de tantos anos... o que a impedia antes era a namorada". 
A resistência vinha principalmente dos/das pobres. Alguns/algumas mencionaram que Dona Margarida tinha sido maltratada e que largar toalhas molhadas no chão era inaceitável. Outros/as criticaram Sérgio por tratá-la como uma "muda de roupas", "vai e volta", "dependente de ter uma namorada". Era claro para alguns/algumas que Dona Margarida merecia um tratamento muito melhor. Além disso, ela era a empregada cuidadora dos sonhos de muitas pessoas, como demonstra Dércio: "se houver afeição pela família ela deve voltar. Eu gostaria que minha empregada tivesse uma ligação emocional com a família, ou pelo menos com a Naomi". Naomi era a filha dele de três anos, e Dércio tinha reclamado da falta de ligação emocional da empregada com ela.

O padrão de relações de gênero, em que a vida doméstica no Brasil se centra nas necessidades do homem, em que a mulher serve e o homem provê, é socialmente difundido e é o padrão ideologicamente dominante mesmo quando a mulher também é provedora. $\mathrm{Na}$ vinheta, ou no que se refere à vida cotidiana real, desencadeada pela estória da vinheta, não era surpresa que os homens não faziam nada em casa. Um tipo especial de patriarca apoia estas relações de gênero sustentado por relações de classe altamente desiguais, que afetam as dinâmicas entre gêneros (BESSE, 1996).

Mais especificamente, diferenças sociais profundas baseadas em classe e "raça" pareciam contribuir para a redução do conflito doméstico nos relacionamentos entre homens e mulheres nos lares mais abastados. Julia Souza (1980) foi uma das primeiras a assinalar o paradoxo de que a liberação de algumas mulheres brasileiras ocorreu ao custo da subordinação de outras mulheres. Ela focou nas implicações econômicas dessas relações de trabalho para o desenvolvimento capitalista, e também refletiu sobre as inconsistências do feminismo brasileiro. A partir disso, Suely Kofes (1982), Sandra Azeredo (1989) e outras também argumentaram que mulheres profissionais estão aptas a prosseguir em suas carreiras porque podem fazer uso dos serviços de outra mulher em casa. Ademais, Danielle Ardaillon (1989) argumenta que a empregada é o maior problema da mulher profissional: primordial para a vida doméstica, sua ausência ou demissão afeta profundamente a rotina da família, e Celma Vieira (1987) enfatiza o progresso mais fácil das mulheres brancas à custa das empregadas negras. Vieira também observa como a área onde as empregadas residem nas casas modernas assemelha-se à estrutura da arquitetura colonial que separava a casa grande das senzalas. Embora poucas famílias tenham empregadas que pousam na casa, o "quartinho" e o banheiro projetados para as empregadas são reveladores do status dos criados, sejam mensalistas ou diaristas. Como Donna Goldstein (2003, p. 80) descreve, a privada geralmente não tem assento, o chuveiro não tem cortina e a água molha todo o cômodo; o quarto com uma cama pequena é usado para armazenar todo tipo de objetos indesejados e fora de uso da casa.

No fim do século $X X$, eu ainda encontrei evidências de que o uso disseminado de criados/as domésticos pelas classes média e alta tem amenizado muitos conflitos sobre a divisão do trabalho doméstico entre gêneros, já que os trabalhos mais servis são dados para as mulheres mais pobres. Como as reações à vinheta demonstraram, as ordens dos homens de classe média para as mulheres de classe baixa eram consideradas mais fortemente como "um direito" do que as ordens de comando entre mulheres.

O estudo foi centrado no sudeste do Brasil, mais rico, mas as divisões sociais entre criados e membros das casas mais abastadas são ainda maiores nas regiões norte e nordeste. O valor do serviço doméstico é mais baixo e as demandas dos ricos por cuidado são maiores onde a pobreza é maior. O preço do trabalho doméstico no Brasil aumenta consideravelmente quando se desce mais para o sul e é ainda maior nas áreas urbanas. Mas mesmo na região mais rica da grande Campinas, empregadas em lares de classe média raramente são autorizadas a usar todas as tecnologias domésticas disponíveis. Isto é consequência do baixo custo do trabalho doméstico e afeta os padrões de desenvolvimento das tecnologias para o lar. Os fogões e máquinas de lavar de boa qualidade são muito caros, ou importados, enquanto os mais baratos dão um trabalho consideravelmente maior para serem operados (SILVA, 1998).

Embora o preço das tecnologias tenha caído com o tempo, o custo do trabalho doméstico não aumentou suficientemente para tornar atrativa a substituição das empregadas pelas máquinas. A renda dos/das mais pobres não é suficientemente alta para gerar novas 
ondas de demanda por tecnologia no lar. Em certos aspectos, isto se ajusta ao modelo de sociedade brasileira que alguns economistas chamam "modernidade excludente" (MILLER, 1991). Ela se baseia na concentração de renda e no consumo sofisticado para uma minoria da população e exacerba as diferenças sociais. $O$ fato de algumas mulheres mais abastadas acharem que precisam ter máquinas de lavar para manter a empregada pode ser um pequeno indicador de uma tendência à diminuição da desigualdade.

\section{Conclusão}

Rememorando os debates feministas nos anos de 1970 nos Estados Unidos, Barbara Ehrenreich (2002, p. 87) escreve que "a nova idéia radical era que o trabalho doméstico não era só o relacionamento entre uma mulher e um coelhinho empoeirado ou uma cama por fazer: era definido também pelo relacionamento entre seres humanos, tipicamente maridos e esposas". Ela continua, dizendo que falar sobre trabalho doméstico era falar sobre poder. 0 rebaixamento do trabalho doméstico não era derivado do fato de ser um trabalho manual, mas do fato de a pessoa a se beneficiar da limpeza ser consistentemente um homem e a pessoa que limpa ser consistentemente uma mulher, tornando o trabalho doméstico uma "declaração simbólica das relações de gênero" (p. 88). Analisando a economia de servidão contemporânea, Ehrenreich observa que "com frequência cada vez maior, quem limpa a casa é uma mulher de cor chegada recentemente do Terceiro Mundo" (p. 102), acarretando o desafio de tornar este trabalho visível de novo. Ela argumenta que "o crescimento da economia de servidão (...) é largamente um resultado da persistência dos homens em abdicarem de suas responsabilidades domésticas" (p. 103). No entanto, o trabalho doméstico não é mais como era antigamente. O contexto atual nos países desenvolvidos é permeado por uma disposição de máquinas, serviços e "produtos semi-prontos" (de comida a roupas e limpadores) como parte do novo "nexo tecnológico" (SILVA, 2002) que permite um novo estilo de vida menos dependente de longas horas dedicadas aos afazeres domésticos. Cuidar de crianças e de outras pessoas e de algumas das tarefas domésticas continuam essenciais para a qualidade da vida cotidiana, mas o contexto é diferente daquele de 1970.

No Brasil, no entanto, a continuidade é mais forte do que nos paises mais desenvolvidos. É claro, muitas das idEias feministas têm sido debatidas no Brasil e muitas têm melhorado produtivamente a posição social das mulheres. Apesar disso, as relações domésticas ainda não foram muito afetadas. $O$ crescimento do trabalho pago das mulheres não mudou os padrões de vida doméstica e as casas continuam sendo administradas pelas mulheres em combinações que envolvem ou não pagamento. Em lares abastados, geralmente não se considera que as relações de gênero requeiram mudanças. As tensões são deslocadas para uma mulher de classe mais baixa, normalmente com a pele mais escura. A habilidade de abrandar conflitos de gênero deste modo tem amortecido objeções aos padrões de gênero tradicionais. Também tem afetado o desenvolvimento tecnológico, pois as demandas pela diminuição dos afazeres domésticos não são mandatórias.

Intervenções governamentais recentes na regulação do serviço doméstico possivelmente forçarão mudanças tanto nas relações de gênero quanto nas inovações tecnológicas no lar, bem como irão melhorar as condições dos/das trabalhadores/as. Em 2006, somente $28 \%$ dos trabalhadores domésticos tinham emprego formal. Ainda assim, medidas oficiais e sanções aumentaram a formalização em 4,6\% entre 2004 e 2006, demonstrando os efeitos da regulação (ILO, 2008). A Constituição Federal de 1988, promulgada depois do regime militar (1964-1985), garantiu novos direitos às trabalhadoras domésticas e permitiu a formação de sindicatos, ampliando a proteção social. Este é o contexto que tem possibilitado a redução do trabalho informal. Os sindicatos, entretanto, como argumenta Dominique Vidal (2008), foram transformados de assistentes sociais a atores judiciais sem receber meios de intervir efetivamente no campo e têm lutado para tomar ações políticas assertivas. Seu sucesso depende de espalhar um senso de justiça, conhecimento dos direitos legais entre as mulheres da classe trabalhadora e consciência da lei.

Dois cenários diferentes exigem reflexão a partir do caso explorado neste artigo. Em um, o serviço doméstico brasileiro regride como aconteceu no Reino Unido nos anos 1930 
(GLUCKSMANN, 1990) e nos EUA depois da Segunda Guerra Mundial (THISTLE, 2006). Uma maior igualdade no lar e a modernização da tecnologia doméstica tornar-se-ão realidade? No outro, o aumento atual no emprego de mulheres imigrantes para o trabalho doméstico na Europa e nos EUA pode vir a afetar o desenvolvimento de máquinas para o lar e a moralidade da vida doméstica cotidiana, diminuindo o ritmo da mudança nas relações de gênero nessas regiões. Os desafios para o pensamento feminista colocados por ambos os cenários são prementes.

\section{Agradecimentos}

O estudo foi financiado, em 1997, pela Universidade de Campinas e pela Capes, no Brasil. Eu agradeço à Patricia Pinho pela sua inestimável assistência de pesquisa na época. Em 2008, eu revisei este estudo com a Dra. Pinho, quando ela visitou a Open University como pesquisadora de estudo financiado pela British Academy.

\section{Referências}

Associação Nacional da Indústria Elétrica e Eletrônica (ABINEE) - (1994 and 2005). A Indústria de Eletrodomésticos no Brasil: informações consolidadas. São Paulo: Abinee.

ALGRANTI, L. (1997) Famílias e Vida Doméstica. In: SOUZA, L. (Ed.). (1997). História da Vida Privada no Brasil. São Paulo: Compania das Letras. p. 83-154.

ANDERSON, B. (2000) Doing the Dirty Work. The Global Politics of Domestic Labour. London: Zed Books.

ARDAILLON, D. (1989) O Cotidiano de Mulheres Profissionais: O Engodo do Individualismo. Ph.D. Thesis, Universidade de São Paulo.

AZEREDO, S. (1989) Relações entre Empregadas e Patroas: Reflexões sobre o feminismo em países multirraciais. In: COSTA, A.; BRUSCHINI, C. (Eds.).(1989) Rebeldia e Submissão. São Paulo: Editora Vértice/Fundação Carlos Chagas.

BESSE, S. (1996) Restructuring Patriarchy. The Modernization of Gender Inequality in Brazil, 1914-1940. Chapel Hill: University of North Carolina Press.

BRITES, J. (2001) Afeto, Desigualdade e Rebeldia: bastidores do serviço doméstico. Ph.D. Thesis, Porto Alegre: UFRGS.

BRUSCHINI, C. (2000) Gênero e Trabalho no Brasil: Novas conquistas ou persistência da discriminação? (Brasil, 1985/1995). In: ROCHA, M. I. B. da. (Ed.). (2000) Trabalho e Gênero. São Paulo: Editora 34.

BRUSCHINI, C. (2007) Trabalho e gênero no Brasil nos últimos dez anos. In: HIRATA, H. (Ed.). (2007). Marché du Travail et genre: comparaisons internationales Brésil-France. Paris: MAGE, CNRS.

EHRENREICH, B. (2002) Maid to order In: EHRENREICH , B.; HOCHSCHILD, A. (Eds.). (2002) Global Woman: Nannies, Maids and Sex Workers in the New Economy. London: Granta Books. p. 83-103.

EHRENREICH, B.; HOCHSCHILD, A. (Eds.). (2002) Global Woman: Nannies, Maids and Sex Workers in the New Economy. London: Granta Books.

EJWS. (2007) European Journal of Women's Studies. Domestic Work, v. 14, n. 3, p. 187-296. 
FINCH, J. (1987) Research note: the vignette technique in survey research. Sociology, v. 21, n. 1, p. 105- 114.

FINCH, J. and MASON, J. (1993) Negotiating Family Responsibilities, London: Routledge.

GITAHY, L., ARAUJO, A.M.C., Alessandra, R., DA CUNHA, A.M. (1997) 'Relações Interfirmas e gestão de recursos humanos na cadeia produtiva de linha branca' Relatório de Pesquisa, FINEP/CEDES/CNPq/ Unicamp.

GLUCKSMANN, M. (1990) Women Assemble, London: Routledge.

GOLDENSTEIN, D. (2003) The Aesthetics of Domination. Class, Culture and the Lives of Domestic Workers' in Laughter out of Place, Berkeley: University of California Press.

HOCHSCHILD, A. (1997) The Time Bind, New York: Metropolitan Books.

ILO (2005) 'Trabalho Doméstico e Igualdade de Gênero e Raça: desafios para promover o Trabalho Decente no Brasil' OIT, Brasil. Acesso em: 13 de março de 2008

$<$ http://www.sei.ba.gov.br/conjuntura/ped/datas_comemorativas/pdf/emprego_domestico_2005. pdf $>$

ILO (2008) 'Mais trabalho decente pra trabalhadoras e trabalhadores domésticos no

Brasil' Acesso em: 6 de janeiro de 2009.

<www.oit.org.br/download/trabalho_domestico_25_04_2008.pdf >

KOFES, S. (1982) Entre nós Mulheres, Elas as Patroas e Elas as Empregadas. In: ARANTES, A.A.; FELDMANN-BIANCO, B.; BRANDAO, C.R.; CORREA, M.; SLENES, R.; KOFES, S.; STOLCKE, V. (Eds.). (1982) Colcha de Retalhos. Estudos sobre a Família no Brasil. São Paulo: Ed. Brasiliense. p. 183-193.

KOWARICK, L. (1987) Trabalho e Vadiagem. São Paulo: Ed. Brasiliense.

LEMOS, C. (1989) História da Casa Brasileira. São Paulo: Contexto.

LOPES, J.R.; GOTTSCHALK, A. (1990) Recessão, Pobreza e Família - A década pior do que perdida. São Paulo em Perspectiva, v. 4, n. 1.

MILLER, L. (1991) Pobreza e Distribuição de renda no Brasil: a década de 80 . Rio de Janeiro: IBGE.

NETO, B. (1992) A indústria de eletrodomésticos de linha branca: tendências internacionais e situação no Brasil. Relatório de Pesquisa. Campinas: Instituto de Economia, UNICAMP.

PNAD. (2001) Pesquisa Nacional por Amostra de Domicílios. Rio de Janeiro: FIBGE.

SAINT-HILAIRE, A. (1820-21 [1974]) Viagem ao Rio Grande do Sul. São Paulo: Edusp.

SALES, T. (1994) Raízes da desigualdade social na cultura política brasileira. Revista Brasileira de Ciências Sociais, v. 25. São Paulo: ANPOCS, p. 26-37.

SARTI, C. (1996) A Família Como Espelho. Um estudo sobre a moral dos pobres. Campinas: Fapesp/Ed. Autores Associados. 
SEADE (2002) O Mercado de Trabalho Feminino na Região Metropolitana de São Paulo. Mulher e Trabalho, n. 7, mar.

SILVA, E. B. (1998) Tecnologia e Vida Doméstica nos Lares. Cadernos Pagu, v. 10, p. 21-52.

SILVA, E. B. (2002) Time and emotion in studies of household technologies. Work, Employment, and Society, v. 16, n. 2, p. 329-340.

SOUZA, J. (1980) Paid domestic service in Brazil. Latin American Perspectives, v. 24, n. VII (1), p. 35-63.

THISTLE, S. (2006) From Marriage to the Market. Berkeley: University of California Press.

TOLEDO, J. C. (1989) Para um levantamento dos impactos sócio-econômicos da automação microeletrônica: Indústrias de Formas - Linha Branca. Relatório de Pesquisa. São Paulo: DIEESE/ FINEP.

TRONTO, J. (1993) Moral Boundaries. A Political Argument for an Ethic of Care. New York: Routledge.

VIDAL, D. (2008) Emerging from dependence: domestic employees' trade unions in Brazil. La vie des Idées. Disponível em: <http://www.laviedesidees.fr/Emerging-fromDependence-Domestic.html> Acesso em: 6 jan. 2009.

VIEIRA, C. R. (1987) Negra: Mulher e doméstica - Considerações sobre as relações sociais no emprego doméstico. Estudos Afro-Asiáticos, v. 14, p. 141-158. 